\title{
9. HIV and the Papua New Guinea Defence Force: Risk Behaviours and Perceptions
}

\author{
JOACHIM PANTUMARI, PETER BAMNE \\ AND VICKI LUKER
}

Questions relating to the military's role in spreading HIV or the impacts of HIV and AIDS on armies place the epidemic in contexts traditionally central to national security (Barnett and Prins 2005; Whiteside et al. 2006; Kershaw 2008; $\mathrm{O}^{\prime}$ Keefe this volume). In PNG, concerns have been raised about the potential for HIV to drain resources from the Papua New Guinea Defence Force (PNGDF), compromise operational capacity, and spread from HIV-positive personnel to their families and to the communities where their work takes them. Fortunately, the PNGDF can exploit certain advantages in tackling HIV, including the institution's organisational structure, an established interest and role in the health of soldiers, and the army's relations with the wider international military community that have facilitated the sharing of knowledge and other forms of cooperation (see e.g., NHASP 26-29; Kendino and Kaule 2005). The PNGDF has demonstrated leadership in aspects of the response.

This chapter focuses on risk factors of infection and perceptions of these within the PNGDF community, drawing on a study undertaken in 2001 and 2002. Its findings remain relevant to measures for limiting HIV's spread within the army, the uniformed services more generally, and the wider civilian population, for many of the behaviours and perceptions identified are not limited to the PNGDF - although some risk behaviours can be accentuated under military conditions (see Eves this volume; Hammar this volume; Jenkins this volume; McLeod and Macintyre this volume).

\section{The PNGDF and HIV}

The structure and role of the PNGDF were inherited from the Australian colonial administration and maintained after independence in 1975 (May 2004; Laki 
and May 2009). Under the Constitution, the principal functions of the defence force are to defend Papua New Guinea and its territory and to assist PNG fulfill its international obligations. In addition, the PNGDF is empowered to provide assistance to civilian authorities under certain prescribed circumstances. These include assistance in the case of a civil disaster; in the restoration of public order and security; in a declared national emergency; and in pursuit of national development and improvement. Due to downsizing, the PNGDF currently employs some 2,000 officers and lower ranks, but when this research was undertaken, more than twice that number were serving - in Headquarters, three battalions, an air wing and a maritime element. The major units are located at Murray Barracks, Taurama Barracks, Landing Craft Base and Kiki Barracks, all in the National Capital District; Goldie Barracks in Central Province; Igam Barracks in Morobe Province; Moem Barracks in East Sepik Province; and Lombrum in Manus Province.

Soldiers come from all over the country, usually from rural backgrounds, and are selected as youths on the basis of physical and academic criteria. As a result of the restructuring program commenced in 2002, the average age of PNGDF servicemen has fallen as many veterans (soldiers who enlisted during the Australian army or colonial eras) have taken the opportunity to retire. The first 21 female recruits were enlisted in late 2009 (Anis 2009), but the army remains an overwhelmingly masculine institution. At the time of the study, the number of soldiers' dependents, mainly wives and children, was estimated in the range of $12,000-18,000$.

The first detected HIV case in a PNGDF soldier was recorded in May 1992, but statistics on HIV within the military are not freely available. In 2004, when concerns were aired about the impact of AIDS on the PNGDF, it was reported that within Port Moresby alone, 108 soldiers had AIDS and the defence force was incurring one or two AIDS deaths per month. Though testing of military personnel had only been limited, HIV prevalence within the army was said to be on a par with concurrent estimates for PNG's population as a whole (Steven 2004). ${ }^{1}$

1 HIV prevalence in some armies has been estimated to be much higher than in the general community (see, eg. Elbe 2003, 17-21). Yet it cannot be assumed that, as a rule, HIV prevalence in armies is higher than in the civilian population. Several factors can influence prevalence. In societies where sexual intercourse is the dominant mode of transmission, young men as a group often have low levels of HIV, and youthful recruits usually comprise a large proportion of the military population. Many armies also screen recruits for HIV (see Whiteside et al. 2006, 202-204). 


\section{Risk Factors and How they are Perceived}

From December 2001 to January 2002 research was undertaken to identify the factors that may expose soldiers to HIV infection; explore the military community's perceptions of such factors; and provide qualitative information for preventive measures. Three methods of data collection were used: focus groups discussions (FGDs), in-depth interviews (IDIs), and document review. The FGDs and most of the IDIs were conducted at Taurama Barracks in Port Moresby. Two IDIs were done outside the Barracks. Part of the document review was done at the Murray Barracks where the Central Medical Records are located. Thirty-five people participated in the FGDs: ten soldiers; seven counsellors; six wives of soldiers; six non-commissioned officers; and six commissioned officers. Thirteen participants from the FGDs then participated in further IDIs. The discussions and interviews were conducted in a mixture of Pidgin and English. The study's findings are summarised below.

\section{Environmental Conditions are Basic Influences on Behaviour}

Participants identified housing as a big problem. Married quarters were chronically overcrowded. Most had been built by the Australian army for soldiers with two to three children, at a time when family planning was actively promoted by colonial authorities. Older soldiers, however, had on average four to six children, some of whom were adults with children of their own, as well as their own parents, residing within the barracks (F. Torova, Director PNGDF Health Services, pers. comm.). Many married soldiers were even worse off. They had no access to married quarters and remained in single barracks, while their spouses and children stayed in the village or in urban squatter settlements. The resulting separation of families had a noticeable impact on the behaviour of servicemen. As one officer remarked, 'You know, when a soldier has no home, wife and children with him, he goes looking for women'. Amenities were a further problem. The soldiers' club had been closed for a decade. Canteen and entertainment services were privately managed and relatively expensive. The gymnasium had no equipment. This lack of amenities, noted one NCO, 'leads to soldiers leaving the barracks and doing silly things'.

Inadequate institutional discipline compounded the problems of poor accommodation and facilities. Soldiers went out at night because there were no barrack bed checks and some resided away from the single barracks without 
lawful permission. Poor regulation of the movement of people in and out of both married and single accommodation was another cause of complaint. Females were regularly smuggled into the single barracks, contrary to the rules.

Low salaries contributed to difficulties. On average, a private earned about K150 (\$A75) a fortnight. One wife remarked that because her husband was a sergeant and she earned a good salary in a bank, they could feed and clothe themselves and their children by pooling their wages. But ordinary soldiers whose wives were not employed and had three or more children could not cope. Moreover, many husbands did not pass their wages to their wives. One soldier suggested that perhaps PNGDF should establish a separate housewife's allowance. For extra money, some wives sold betel-nuts, cigarettes, twisties and alcohol in the informal sector, while a few sold sexual favours. As one counsellor remarked, 'Because the life is hard, the extra income from such affairs supplements the family income... often times the husbands allow it to happen'.

Lack of funding for annual leave entitlements was identified as another harmful factor. It prevented some soldiers from uniting with their wives and children, while others were unable to take their families to their home provinces during leave, thereby depriving children of the chance to learn the traditional values that participants thought could contribute towards their decent upbringing.

Nor was PNGDF providing incentives through further training, staff development, and promotion. The range of training opportunities had shrunk and stagnated since 1989, when the Bougainville crisis drained PNGDF's resources. Trade specialisation courses for caterers, medical assistants, storemen, signallers and the like, some of which had formerly been conducted in Australian military schools under the auspices of AIDAB (now AusAID) and the bilateral defence agreements, were no longer offered. The training repertoire had shrunk to military weapons handling, drills and military personnel managementlargely incompatible with civilian service skill sets and therefore offering few opportunities for a livelihood beyond the PNGDF. With limited training opportunities combined with ineffective promotion procedures, many soldiers evidently saw little point in trying or planning for better things. Despite much reform since 2002, grievances about pay and conditions remain (Anon. 2007).

\section{Awareness of STIs and HIV/AIDS}

Among participants, understandings and perceptions of STIs varied, but all stated that STIs were transmitted through sexual intercourse and identified gonorrhoea as the most common infection. The discussions also showed the difficulties facing army wives. One recalled: 
It took me about 3 years to become pregnant with our first child after our marriage. My husband did not have a house so I stayed in a girls' hostel in Port Moresby. He visited me at opportune times, usually when he was drunk... I had two abortions [miscarriages]. I was also treated for abdominal pain, going to the toilet frequently, pain on passing urine and offensive discharges from the birth canal. I was afraid to sleep with my husband ... it was painful at times. On all occasions, the sisters diagnosed me as having PID [pelvic inflammatory disease]. I think, [tries to explain] it is a form of the illness. Twice I had to consult a medical officer. I am glad this is all over for me.

Another wife described how she would try to prevent an STI from getting into the family:

I would talk with him [husband]. We ladies, we have our own rights. Even if he beats you, you have to persist in talking to him... It is hard to stop it getting into the family, especially when the husband brings it ... We just have to seek medical treatment. I cannot take up the issue with him directly. He is a man ah! In the white man's culture they understand each other - but for us Papua New Guineans, man [sic] say they are the bosses. They know everything and for the women they say, 'You are dirt. You belong to the home.' If I can't talk to him directly, personally myself, if I see him having affairs outside of the home, then I could go and seek counselling officer, or maybe I could get my family over ... We ladies could feel, if the husband is having affairs outside the house. He normally gets angry over trivial things, he might belt you for no good reason and there is no more harmony ... He could get all the money and spend it with ladies. The only way to sort this out with him, as a wife I should get my family over, maybe get the church members over, sit down and solve this [sic] things. As soldiers' wives we know that soldiers are not very faithful when they go for operations. As for my case, I normally tell my masta [husband]. If I see that something is not right I will tell my husband to go and get tested. We don't want to die quickly because we have kids. We ladies, we are strong. We can stay [i.e. be faithful] without husbands. It's only a few mothers who do things ... majority of mothers we stay, ah. The only thing is our husbands, our husbands. They can't stay by themselves long. They want to enjoy themselves. For the safety of my kids, because I don't want to lose my kids, leave my kids hopeless, helpless, and motherless children, I will ask him to get tested... If he does not want to go, I could go on behalf of him and get tested. If I have it then it is him who gave it to me. 'I am an honest mother.' That's what I tell my husband. 'If you do not want to go, if [you] are staying in the house, then I will go on behalf of you.' 
Participants knew that HIV is transmitted sexually, and some acknowledged other modes, such as mother to child. A few said that HIV is a curse from God for humanity's mischief, and one of the wives mentioned buriburi or magic by sorcerers, with which two others agreed (cf. Haley this volume). Beliefs concerning the treatment of AIDS differed widely. Some participants were certain that cure was possible by divine intervention and medicinal herbs (cf. Hammar this volume; Eves 2008). They understood that no cures for AIDS were available by conventional modern medicine and at that time antiretroviral therapies were hardly known and scarcely available in PNG.

All maintained that safe sex behaviours should be sex with one regular partner within marriage, use of condoms, adherence to Christian principles and avoiding places where sex is available. Soldiers accepted that their behaviours, in practice, were risky and one of the women expressed a common frustration of the wives:

Anybody can contract HIV infection. I can get it from my husband or other way around. I do not trust my husband, he drinks and mixes around with his work-mates. I tried to discourage him but he cannot listen to me. He causes fights and go [sic] further non stop... At this point, I give up. I am fed up already. To be honest, I am very scared of my husband's behaviour. When he is drunk, he disregards the use of condom. I have to submit because he can be violent. I am in constant fear for my health and sometimes I am feel [sic] like committing suicide.

\section{Risk Behaviours}

Many of the risky behaviours of soldiers are no different from those of civilians. They include several forms of multi-partnering and the rejection or inconsistent use of condoms. Participants particularly discussed brothels and group-sex or lainap (cf. Jenkins this volume).

Close to the Taurama Barracks are a number of facilities for sex. One is at ThreeMile beside Port Moresby General Hospital, where soldiers go 'because the sex offered by commercial sex workers is cheaper at about K10.00 per go ... The other such outlet is in the precincts of Bisini Parade Ground where street vendors go for sex at a rate of K2.00 per go' (see Hammar this volume; Fletcher and Gonapa this volume; Stewart this volume). Habitual clients of sex-workers, noted one counsellor, 'are those with welfare problems such as separation and divorce, lack of institutional accommodation, and being rejected by their wives for fear of STIs and debilitating medical condition of their spouses'.

The practice of visiting brothels was not questioned by either soldiers or their wives. Soldiers felt that the government should legalise the sex industry so 
there could be controls in place to check the spread of diseases (cf. Hammar this volume; Fletcher and Gonapa this volume). As one of the officers commented, 'I would like to ask if the government could legalise things like brothels. This is to stop the little 'corner activities' which are done with a lot of risks'.

Lainap or 'line-up', also known as 'ATM' and by other terms, refers to several men having group sex with a woman. It can be a most effective way of spreading HIV (cf. Jenkins this volume; Jenkins 1996, 204) and appears to be commonly practised in the army. Condoms are sometimes worn, but the mood of the moment and the associated use of intoxicants militate against their use. According to informants in this study, pornography, and the consumption of alcohol and marijuana are often implicated in lainaps and other risky sexual activity.

To the question, what actually happens in lainap, one soldier explained, 'Doctor sir, lainap long unit XXXX, em everybody with pants down, some with condoms on, some "negative", "pure". Meri em lie down long bed. Taim man i enterim room, em tok 'bend down', em meri bend down, em givim. [Doctor, sir, line-up at unit XXXX is everybody with pants down, some with condoms on, others without condoms. When a man enters the room, he says, 'Bend down' and the lady bends down and he does it]... However some times three to one. Wanpela long maus, wanpela long kan, wanpela long as [one orally, one vaginally, and one anally].' If one man takes too long, they call "Hariap, hariap, kapsait hariap na next one" [hurry up, hurry up, release quickly and next one].'

The number of men said to be involved can range from a few to as many as a whole battalion. Soldiers in the FGDs commented, 'In a single barrack, the entire barrack's occupants could take part', up to 100 to 200 men, depending on the lady's attitude: 'Some would call out and stop the event but others can continue'. While the men participating could be either single or married, lainaps almost always occur in the single barracks.

The women involved, according to one counsellor, 'come from different sources':

Sometimes it is daughters or relatives of soldiers living within the barracks... Some parents do not know of their daughters' activities. Some ... turn a blind eye.

Others are picked up at nightspots. Some come from brothels. Some, it was said, do it for fun and pleasure. Others do it for financial reasons but this seems rare. Others are forced. This force could be applied directly outside the barracks to bring the female in, or applied after she had entered the barracks voluntarily. 


\section{Condoms}

Male condoms have a relatively long history in the PNGDF. They were originally introduced by the Australian army as a means of family planning and preventing STIs. At the time of this study they were provided as part of the standard ration pack, and were also available through the health service for soldiers, spouses and their teenage children. Most people in the study understood the use of the male condom. The female condom seemed less known. Health workers had never demonstrated it to the wives.

Male condoms were in some measure accepted by soldiers. As one NCO remarked, 'Carrying condoms in your ration pack is like wearing your boots. It is similar to any safety precaution you take like wearing your helmet or boots. Therefore carrying condoms as part of your ration pack is a good idea'. Wives too, as one of the extracts has already illustrated, saw condoms as providing some protection against STIs. But a number of qualifications about condoms emerged in discussion and reflect views held in the broader community.

Among men, the popular attitude of 'flesh to flesh is real sex' seemed to prevail: 'Still many soldiers are not using condoms despite being available free. Many soldiers prefer sexual intercourse without condoms because they say it is more satisfying. The common saying is "flesh to flesh is much better than gumi [condom] and flesh".'

Several participants, and nearly all the wives, thought that condoms did not offer 100 percent protection. They claimed to have witnessed STIs, pregnancies and lately HIV infections in couples who used them. It was unclear whether the study participants thought that a defect in the condoms was to blame, or human failing by not using them consistently (cf. Wardlow 2008, 196-197). As one of the quotes above has indicated, wives certainly saw alcohol as causing men to lose self-control and thus compromise the use of condoms, while more fundamentally both men and women described the male sex drive as precluding right thinking and careful action.

Wives also maintained that condoms promoted promiscuity and this view was prevalent among the soldiers themselves: 'With issue of condoms I feel that we are encouraging sex'; 'If they do not have condoms, the fear of acquiring sickness can act as a deterrent'; and 'Condoms should be discouraged. It encourages sex so government should do away with condoms'. 


\section{Male Bonding, Sexual Development and Sex Drive}

Among the factors that male participants mentioned as influencing their sexual behaviour were: peer pressure; the way men developed sexually within the culture of PNGDF; and the male sex drive (cf. Eves this volume; Jenkins this volume). Soldiers acknowledged the irresistible force of male bonding. 'You will see that in the disciplinary forces, it's a bit different to the civilians. There is a kind of bond or comradeship among the troops. So when a mate brings a woman and tells his mate, and if his mate refuses, he will say, "You must be a woman. You talked of bringing women and you did not show up". This comradeship exists ... If the mate refuses, that mate will be told, "You are not my good mate".'

The pressure to conform is almost impossible for a man to withstand. One soldier confessed, 'Mi pret long mi yet [I am so very scared]. I cannot have that courage to say that, "Gentleman, No. Thank you for the offer, I have to go. I have a family to look after. Here is K5.00. Put it together and buy your beer but I have to go home". There is no courage in our soldiers. If only I had the courage.'

Soldiers also noted that the army shaped the development of soldiers' adult sexual behaviours. Recruits join the force as youths. Some have little prior experience of sex or of dealings with members of the opposite sex. If their sexual initiation takes the form of risky sexual acts, this will, they believed, affect the soldiers' later life. In the FGD, participants commented on the lack of sex education for kids and teenagers. For recruits, "the sex education they get is the existing "sex culture" of the defence force'. In the army, young men do not have the opportunity to develop their character through civilian activities outside the military community and in day-today interaction with women. As one explained:

We go out to do our shopping, banking, or military exercises and we come back. We do not have much association with women through civic exercise. That is why planti taim yumi ol soldier go out long nait club na yumi come across long ol meri, yumi laik, just go there and drink, na our aim is to grab a women, come back to our unit, na enjoyim pleasures wantaim em [That is why, often when we go out to night clubs, our aim is to go, drink, grab a women, come back to our units and enjoy pleasures with her.]

Soldiers (and their wives) also believe that men are subject to an overwhelming sexual drive. In the words of one soldier, 'Mi no tok body pleasure-body pleasure em in English. Mi tok Pidgin, em body blong me needim. Body blong mi em needim tru [I am not saying body pleasure... body pleasure, it's English. If I say it in Pidgin, my body really needs it. My body really needs it.] [Facial 
expression indicating a desperate need of something].' The remarks of another soldier also show one of the ways in which defence personnel may serve as bridges of infection in communities to which military operations take them:

OK, the problem now comes back to us and our desires. How can we control our desires? Soldier is a colourful man in the world. When the soldier goes in full battle gear into a village all the ladies are saying, 'Look! That guy with the big bag - he is the medicine man, oh! That guy must be the boss!' [said with pointing fingers, eyes wide with wonder]. Three ladies will come to me, another four will go to another guy. How can I control myself?

\section{The PNGDF's Response to HIV and AIDS}

In many respects, the PNGDF has been in the forefront of the response to HIV in PNG. Army medical personnel, since their involvement in the care of the country's first reported case of AIDS in 1987, have contributed significantly both to the national response and more particularly to the PNGDF's. The army was the first government body to frame an HIV/AIDS policy, under which HIV-positive soldiers are protected from discrimination and allowed to remain within the force. When HIV-positive personnel are discharged, it is usually at their own request, and they are allowed to resign with full entitlements. In 2004 an HIV Committee was formed at PNGDF Headquarters to coordinate all levels of response.

Soldiers who are sick are cared for either in hospital or at home. Medical treatment for soldiers is free of charge. The PNGDF's medical capacity to deal with HIV has been building, through general efforts to upgrade army health facilities and training, for instance through the PNGDF's partnership with the Chinese National Defence Ministry (Gerawa 2008; Wakus 2005), and through specific measures targeting HIV and AIDS. Since 2005, the US Department of Defense HIV/AIDS Prevention Program (DHAPP), in collaboration with Joint United Nations Program on HIV/AIDS, AusAID, Family Health International and PNG National AIDS Council, has funded the renovation and outfitting of five voluntary counselling and testing centres for the military - at Taurama Barracks, Murray Barracks, Goldie Barracks, Igam Barracks and Moem Barracks - and necessary training for counsellors, pharmacists, nurses and physicians (DHAPP 2006). The PNGDF also supports a program for home-based care for people living with HIV that involves a cross-section of the PNGDF community while military sites have been targeted by major programs supporting community responses to HIV, such as the Tingim Laip ('Think about Life') Project (NHASP 2006, 26-29; Elder 2008, 12-19; 26-31). HIV initiatives within the army may have produced a relatively high awareness of HIV. Among adult male workers in private industries and the 
military surveyed for the National AIDS Council Secretariat, soldiers were the group with by far the most comprehensive knowledge of HIV and its prevention, and the most positive attitudes to people living with HIV or AIDS (NACS 2006, 31-32). The PNGDF has also assumed a role in the warehousing and distribution of condoms, following publicity about the fact that millions of condoms ordered by the National Department of Health had languished in storage and passed their use-by date (Taimbari 2009; Joku 2009).

The authors of this chapter remain grateful to the men and women who generously contributed to this study and to the PNGDF leadership for their response to HIV within the force. In conclusion we stress that many of the risks participants identified and the perceptions they shared, if often accentuated by army conditions, reflect risks and perceptions in the broader community too. In discussing some sexual behaviour as risky or destructive, many participants expressed personal ambivalence and even unhappiness. This in turn, suggests the possibility of traction for change in this difficult area.

\section{References}

Anis, Alison. 2009. Women Recruits Take up Duties as Soldiers. National, 7 December 2009.

Anon. 2007. Parade Called Off. PNG Post-Courier, 7 December 2007.

Barnett, Tony and Gwyn Prins. 2005. HIV/AIDS and Security: Fact, Fiction and Evidence. A report to UNAIDS. London: London School of Economics. Available. http://www. lse.ac.uk/collections/DESTIN/publink/barnett/asb06a.htm (accessed 27 April 2010).

DHAPP (DoD HIV/AIDS Prevention Program). 2006. DoD HIV/AIDS Prevention Program (DHAP) Activity Report January-March 2006. Papua New Guinea.

Elbe, Stefan. 2003. Strategic Implications of HIV/AIDS. International Institute for Strategic Studies, Adelphi Paper 357. Oxford: Oxford University Press.

Engels, John. 2008. Tingim Laip: Success Stories from New Guinea. Waigani: Family Health International.

Eves, Richard. 2008. Moral Reform and Miraculous Cures: Christian Healing and AIDS in Rural New Ireland, Papua New Guinea. In Making Sense of AIDS: Culture, Sexuality, and Power in Melanesia, ed. Leslie Butt and Richard Eves, 206-223. Honolulu: University of Hawai'i Press.

Gerawa, Maureen. 2008. Chinese Team Opens Clinic. Post-Courier, 13 June 2008.

Jenkins, Carol L. 1996. The Homosexual Context of Heterosexual Practice in Papua New Guinea. In Bisexualities and AIDS: International Perspectives, ed. Peter Aggleton, 191-206. Bristol, Pa: Taylor and Francis. 
Civic Insecurity

Joku, Harlyne. 2009. 2 Million Condoms go to Waste! Post-Courier, 4 March 2009.

Kendino, Gideon H and Ralph D. Kaule. 2005. HIV/AIDS Military Study Tour Report. National HIV/AIDS Support Project, High Risk Settings Strategy Report: Moving beyond Awareness. Milestone 90, Annex 7, 64-68.

Kershaw, R. J. 2008. The Impact of HIV/AIDS on the Operational Effectiveness of Military Forces. ASCI Research Report No. 4, April 2008, AIDS, Security and Confict Initiative. www.asci.ssrc.org.

Laki, James and R. J. May. 2009. Policy Making in Defence. In Policy Making and Implementation: Studies from Papua New Guinea, ed. R. J.May, 261-279. Canberra: ANU E Press.

May, R. J. 2004. Government and the Military in Papua New Guinea. In Military and Democracy in Asia and the Pacific, ed. R. J. May and Viberto Selodian, 148-175. Canberra: ANU E Press.

NACS (National AIDS Council Secretariat). 2006. HIV/AIDS Behavioural Surveillance Survey within High Risk Settings. BSS Round 1. [Boroko]: National AIDS Council Secretariat.

NHASP (National HIV/AIDS Support Project. 2006. High Risk Settings Strategy Report: Moving Beyond Awareness. Milestone 90. Revised July 2006.

Pantumari, Joachim and Peter Bamne. 2002. A Perception of Factors Associated with HIV/AIDS Infection among Soldiers in Port Moresby, Papua New Guinea. Masters of Public Health Thesis. Port Moresby: University of Papua New Guinea.

Steven, Charles. 2004. Epidemic Threatens Grave Ravages for our Defence. PostCourier, 8th July 2004: 16.

Taimbari, Fredah. 2009. PNGDF Allocates Warehouse for Condom Storage and Distribution. Bung Wantaim 13: 2.

Wakus, Wanita. 2005. Training for Army Doctors. Post-Courier, 3 October 2005.

Wardlow, Holly. 2008. 'You have to Understand: Some of Us are Glad AIDS has Arrived': Christianity and Condoms among the Huli, Papua New Guinea. In Making Sense of AIDS: Culture, Sexuality, and Power in Melanesia, ed. Leslie Butt and Richard Eves, 187-205. Honolulu: University of Hawai'i Press.

Whiteside, Alan, Alex de Waal and Tsadkan Gebre-Tensae. 2006. AIDS, Security and the Military in Africa: A Sober Appraisal. African Affairs 105/409: 201-218. 